\title{
IDENTIFIKASI ALUN-ALUN KUDUS SEBAGAI FASILITAS RUANG TERBUKA PUBLIK DI TINJAU TERHADAP PENDEKATAN DIMENSI FUNGSI DAN DIMENSI SOSIAL
}

\author{
Rizqi Jamaluddin \\ Megister Teknik Arsitektur Universitas Diponegoro \\ Penulis Korespondensi e-mail : ratihsaris@yahoo.com
}

\begin{abstract}
:
In a city it is the most complicated creation, taste, intention, and human work throughout civilization. The city can be regarded as a crowded place and inhabited by heterogeneous (diversified) people in terms of livelihood, religion, customs and culture. On a network of custom houses with high population with socio-economic strata. The physical characteristics of a city vary greatly but the physical characteristics of a design city must have economic facilities such as markets or supermarkets, adequate parking space, recreational and sports venues, squares, government buildings, Kudus is the city with all its beauty. Of the 35 cities and regencies in Central Java, Kudus has an area of $425.5 \mathrm{sq}$. Km. One of the most unfortunate ones is the open space or open space that can be used publicly. Kudus city has an open space which is also owned by other cities, namely the square which is one of the landmarks that exist in the sanctuary. Being in the middle of the city makes this Kudus square always crowded in the place of people from various cities because almost all the way is centered to this square. Various elements which is the most important element in the arrangement of urban space. It is interesting to be studied because there are still many things that need to be studied and meticulously in the square kudus. Analyze case studies on the researchers will use 2 (two) theory. The goal is to know what elements of the elements exist in the city zone in the holy city. The author conducts research in the field with the aim of collecting data contained in and assisted by the literature and others.
\end{abstract}

Keywords: Kudus Square, Urban Dimension, Urban Space

\begin{abstract}
ABSTRAK
Dalam sebuah kotamerupakan hasil cipta, rasa, karsa, dan karya manusia yang paling rumit sepanjang peradaban. Kota bisa dibilang sebagai tempat yang padat dan dihuni oleh orang-orang yang heterogen (beraneka ragam)baik dalam hal mata pencaharian, agama, adat, dan kebudayaan. Pada sebuah kota kesatuan jaringan kehidupan manusia ditandai dengan kepadatan penduduk yang tinggi disertai dengan strata sosial ekonomi. Ciri fisik sebuah kota sangat beragam akan tetapi ciri fisik sebuah kota jika dilihat dari seorang urban design harus mempunyai Sarana perekonomian seperti pasar atau supermarket, Tempat parkir yang memadai, Tempat rekreasi dan olahraga, Alun-alun, Gedung-gedung pemerintahan, Kudus adalah kota dengan segala keindahannya. Dari 35 kota dan kabupaten di Jawa Tengah, Kudus memiliki luas $425,5 \mathrm{~km}$ persegi. Salah satu unsur yang penting dalam suatu kota adalah ruang terbuka atau open space yang dapat digunakan untuk aktivitas umum. Kota kudus memiliki ruang terbuka yang juga dipunyai oleh kota-kota lain, yaitu alun alun alun alun kudus sendiri merupakan salah satu landmark yang ada di kudus. Berada pada tengah kota membuat alun alun kudus ini selalu ramai di kunjungi masyarakat dari berbagai kota karena hampir semua jalan terpusat ke Taman alun alun kudus ini. Terdapat berbagai macam elemen yang dimana merupakan elemen terpenting dalam menataan urban space.Hal ini menarik untuk diteliti dikarenakan masih banyak hal hal yang perlu dipelajari dan di teliti di alun-alun kudus.Dalam menganalisa studi kasus di atas peneliti akan mengunakan 2 (dua) teori . Tujuan penulis adalah untuk mengetahui elemen elemen apa saja yang terdapat pada kawasan kawasan yang ada di kota kudus. Penulis melakukan observasi singkat dilapangan dengan tujuan mengumpulkan data kongkrit yang berada di sana dan dibantu oleh literature dan sumber yang lain.

Kata kunci: Alun-Alun Kudus, Dimensi perkotaan, Urban Space.
\end{abstract}




\section{PENDAHULUAN}

Kota merupakan salah satu ungkapan kehidupan manusia. Kebanyakan para ilmuwan berpendapat bahwa ungkapan kota sebagai ekspresi kehidupan orang sebagai pelaku dan pembuatnya. Hal tersebut disebabkan karena permukiman perkotaan tidak memiliki makna.yang jelas adalah kenyataan bahwa kawasan kota juga memiliki sifat yang sangat mempengaruhi kehidupan tempat tinggalnya. Kenyataan tersebut dapat diamati dimana suasana kota kurang baik dan dimana masyarakatnya tidak nyaman akan tempat tinggalnya. Kota sebagai kesatuan jaringan kehidupan manusia yang ditandai dengan kepadatan penduduk yang tinggi dan diwarnai dengan strata sosial ekonomi yang heterogen serta coraknya materialistis. Masyarakat kota terdiri atas penduduk asli daerah tersebut dan pendatang. Masyarakat kota merupakan suatu masyarakat yang heterogen, baik dalam hal mata pencaharian, agama, adat, dan kebudayaan. Sedangkan Max Weber mendefinisikan kota adalah suatu tempat yang penghuninya dapat memenuhi sebagian besar kebutuhan ekonominya di pasar lokal. Ciri kota adalah adanya pasar sebagai benteng serta mempunyai sistem hukum tersendiri dan bersifat cosmopolitan (Bintarto, 1989).

Perancangan kota adalah proses dari konsep dan realisasi arsitektur yang memungkinkan penguasaan pengaturan formal dari perkembangan kota, yang menyatukan perubahan dan kemapanan. Konsep perencanaan dan perancangan kota yang mencoba mengakomodasikan seluruh prinsip yang ada yaitu antara lain konsep mengenai pembangunan yang berorientasi pada sistem transit/transportasi (TOD), konsep perumahan dengan kepadatan tinggi dan konsep mengenai pemanfaatan tapak yang multifungsi, dengan fungsi hunian sebagai intinya, hingga konsep mengenai kota yang terpadu (compact city) berbasis pada lingkungan hunian (Nugroho, 2009)

Salah satu kabupaten di Provinsi Jawa Tengah yang berpotensi dalam adalah Kabupaten Kudus. Kota yang mempunyai julukan sebagai kota kretek ini mempunyaI perkembangan morfologi yang sangat pesat dari tahun ke tahun. Hal ini di tunjukan dengan semakin majunya sarana dan prasarana yang ada di kota tersebut. Secara administratif, Kabupaten Kudus terbagi dalam 9 kecamatan, 123 desa, 9 kelurahan. Kecamatan yang terluas adalah Kecamatan Dawe yaitu sekitar 8.584 Ha (20,19 \% ) sedangkan yang paling kecil adalah Kecamatan Kota seluas 1.047 Ha ( 2,46 \% ) dari 
luas Kabupaten Kudus. Sebagian besar jenis tanah di Kabupaten Kudus adalah aluvial coklat tua sebesar 32,12 \% dari luas tanah di Kabupaten Kudus. Dimana sebagian besar tanahnya memiliki 0,2 derajat dan kedalaman efektif lebih dari $90 \mathrm{~cm}$. Kudus dulunya bernama "Tajug" .Secara harafiah tajug berarti bangunan diatas makam yang beratap perisai dengan satu puncak. Nama Tajug, terdapat dalam 'Serat Kandha', yang diikhtisarkan oleh Brandes (dalam Graaf, 1985)

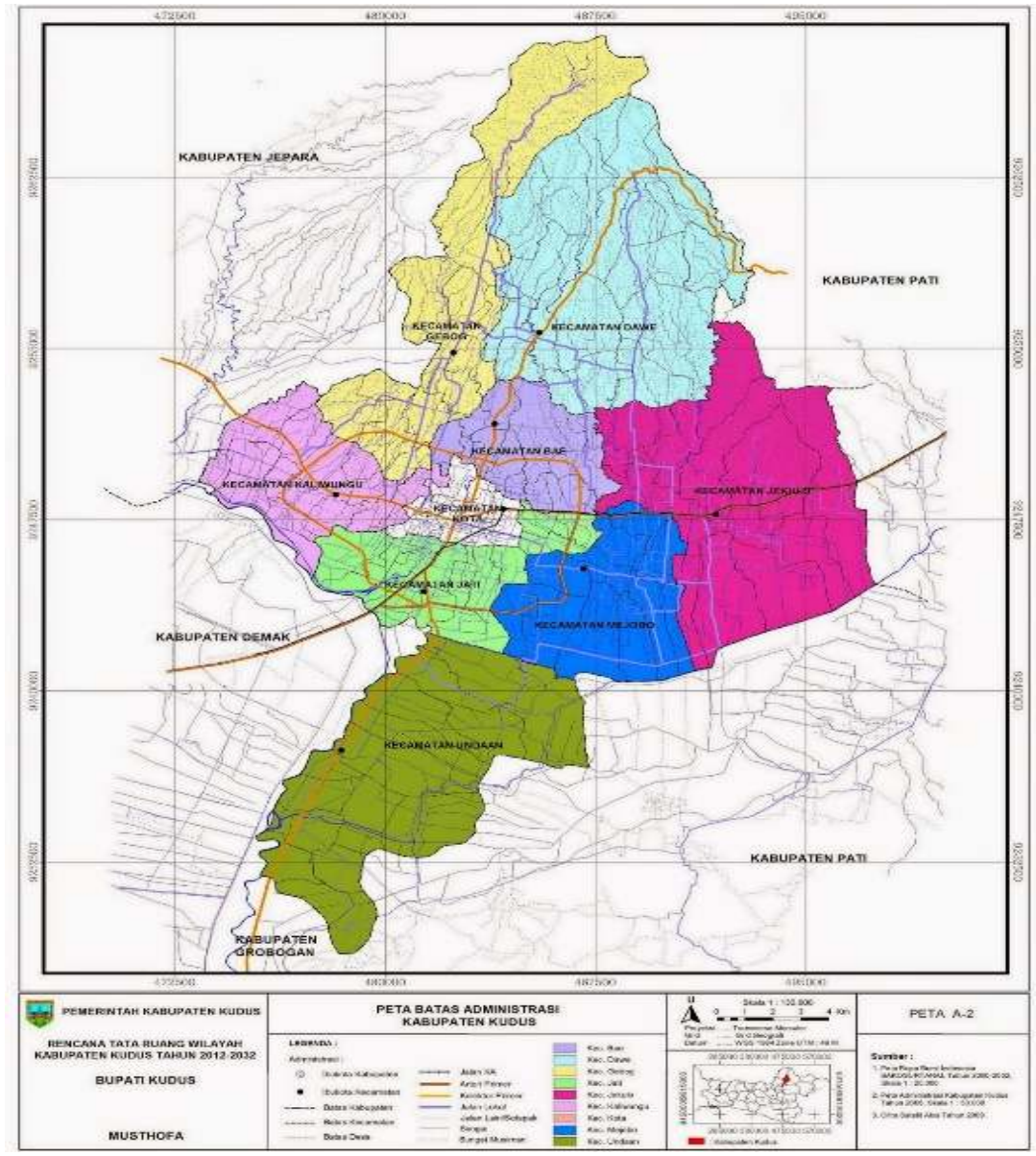

Gambar 1. Peta Administrasi Kabupaten Kudus Sumber: penataanruangjateng.info, 2018

Kudus merupakan salah satu kota di daerah pesisir utara jawa yang merepresentasikan kebudayaan Pesisiran. Masyarakat Kudus adalah masyarakat muslim yang taat, disamping itu juga dikenal sebagai masyarakat pedagang yang ulet dan tangguh. Oleh karena itu masyarakat Kudus dijuluki sebagai masyarakat Pedagang 
Santri. Kudus merupakan sebuah kota santri dengan berbagai macam elemen pembentuk kota nya. hal ini didasari salah satunya dengan adanya alun alun.

Alun-alun Kudus sudah memegang peranan penting, pada abad ke 18 Kudus ada dalam kekuasaan Belanda, pada saat itu Kudus merupakan daerah dengan tingkat kabupaten. Beranjak pada abad 19, terjadi perpindahan perkembangan kota menuju arah sebelah Timur Kali Gelis (Kudus Wetan), perpindahan ini juga diikuti oleh berdirinya alun-alun kota yang baru (Sardjono, 2017). Hingga saat ini di dalam alun alun kudus banyak terdapat aktivitas kegiatan masyarakat. Kegiatan itu di wadahi kedalam sebuah open space dengan berbagai elemen pendukung yang dapat membantu kegiatan masyarakat. Di dalam alun alun sendiri selain mempunyai fungsi dan manfaat yang bermacam macam juga tidak terlepas dengan permasalahan. Mungkin dari segi elemen di dalam alun alun nya atau mungkin didalam penataan nya. Jika ditarik sebuah kesimpulan sederhana, ruang publik merupakan ruang yang bekeria dengan memakai landasan wacana moral praktis yang melibatkan interaksi secara rasional maupun kritis dibangun dengan tuiuan untuk mencari pemecahan masalah-masalah hal ini bisa dipahami sebagai ruang yang menyediakan dan melibatkan publik secara lebih luas dalam mendiskusikan realitas yang ada (Nasrullah, 2015).

Lebih jauh Thomas Nix (dalam Nugroho, Suryono dan Setiawan 2010) menjelaskan bahwa alun-alun merupakan lahan terbuka dan terbentuk dengan membuat jarak antara bangunan-bangunan gedung.Jadi dalam hal ini, bangunan gedung merupakan titik awal dan merupakan hal yang utama bagi terbentuknya alun-alun. Tetapi kalau adanya lahan terbuka yang dibiarkan tersisa dan berupa alun-alun, hal demikian bukan merupakan alun-alun yang sebenarnya. Jadi alun-alun bisa di desa, kecamatan, kota maupun pusat kabupaten. Sesuai dengan definisi alun-alun merupakan suatu lapangan terbuka yang luas dan berumput yang dikelilingi oleh jalan dan dapat digunakan kegiatan masyarakat yang beragam. Ruang terbuka hijau merupakan suatu wadah yang dapat menampung aktivitas masyarakat baik berkelompok maupun individu (Hakim,1987). Menurut Edi Darmawan (2003) ruang terbuka berfungsi sebagai tempat bermain, berolah raga, tempat bersantai, tempat komunikasi sosial, tempat peralihan menunggu, sebagai tempat untuk mendapatkan udara segar dengan lingkungan, sebagai sarana penghubung suatu tempat dengan lainnya, sebagai pembatas/jarak antara masa 
bangunan, dan mempunyai fungsi ekologis yaitu penyegaran udara, menyerap air hujan, dan pengendalian banjir. Jadi dapat disimpulkan bahwa ruang merupakan suatu wadah yang tidak nyata akan tetapi dapat dirasakan keberadaannya oleh manusia, dan ruang merupakan penghubung antara manusia dengan alam. Hal ini menunjukkan betapa pentingnya peranan ruang terbuka hijau sebagai salah satu elemen perkotaan. Alun alun sendiri berfungsi sebagai berinteraksi dan saling bertukar informasi. Tinjauan pembahasan kota akan mencakup tentang Teori Functional Dimension dan Teori Sosial Dimension, serta perkembangan aspek peraturan kota atau pranata kota.

\section{METODOLOGI}

Metode yang digunakan adalah metode kualitatif dengan analisis observasi dilakukan untuk memperoleh data letak dan luas taman, iklim mikro, fasilitas, vegetasi dan keindahan. Metode observasi dilakukan dengan pengamatan obyek melalui alat pengukur (Zahra, 2014). Dimensi fungsional adalah disain urban yang berkaitan dengan bagaimana tempat dan bagaimana perancang perkotaan dapat membuat tempat tersebut menjadi 'lebih baik' dalam hal meningkatkan potensi pengembangannya. Dimensi desain kota ini dijelaskan dalam Tiga bagian:
a. Gerakan (movement)
b. Ruang Sosial (The Sosial Of Space)
c. Desain lingkungan (Environmental Design)

\section{a. Gerakan (Movement)}

Gerakan sangat mendasar untuk memahami bagaimana fungsi tempat. Pejalan kaki bergerak melalui ruang publik di mana orang memilih duduk atau berlama-lama di ruang publik dan terkait dengan kehidupan dan aktivitas di dalam ruang.Pada sebuah ruang terbuka terdapat juga berbagai macam pergerakan seperti kendaraan.Pergerakan dalam public space merupakan jantung dari urban experience, faktor utama adalah pembangkitan kehidupan dan aktivitas.

Jika sebuah ruang tidak terletak dengan baik dalam pola pergerakan lokal, tidak masalah seberapa bagus rancangannya karena tidak mungkin digunakan dengan baik kecuali ada perubahan di area yang lebih luas - kepadatan penggunaan atau perubahan 
yang lebih baik pada jaringan pergerakan.Yang meningkatkan konektivitas dan / atau mengurangi pesangon (yaitu melalui koneksi kualitas yang lebih baik atau dengan koneksi baru, seperti jembatan baru di seberang sungai, atau penghilangan hambatan untuk bergerak ke lokasi).

\section{b. Ruang Sosial (The Sosial Of Space)}

Maraknya pembangunan diberbagai tempat membuat banyak orang merasa kehilangan tempat/wadah untuk melakukan interaksi. Keberadaan Alun-alun selain berfungsi sebagai public space juga sebagai ruang terbuka hijau kota sekaligus dapat sebagai landmark kota, diharapkan dapat menjawab keinginan masyarakat untuk menjadikan alun-alun sebagai kawasan yang asri dan menjadi kebanggaan masyarakat (Santoso, 2008).

Sebuah ruang memiliki dua fungsi yang signifikan, ruang dapat menyatukan sekelompok orang dan juga secara simultan ruang juga dapat memisahkan sekelompok orang satu sama lainnya (Zhang dan Lawson, 2009). Ruang merupakan hal yang sangat esensial juga fundamental dan universal dari bentuk komunikasi. Ruang yang mengelilingi manusia dan objek-objek yang berada di dalamnya dapat menentukan seberapa jauh manusia dapat bergerak, seberapa hangat atau dingin kita merasa, seberapa banyak yang dapat kita lihat dan dengar, dan dengan siapa manusia dapat berinteraksi. Realitas ruang tidak hanya terbatas menggunakan dimensi fisik dan waktu, namun juga dimensi 'energi' yang dipancarkan masing-masing material. Energy ruang akan memberikan pengaruh pada karakter lingkungan sosial, karena ia bergerak dalam proses komunikasi sosial. Dengan demikian ruang di samping menunjuk pada material dan waktu, juga berfimensi komunikasi sosial, karena dalam mengekspresikan hasil olah pikirnya (materi ruang) manusia membutukan komunikasi sosial agar karyanya bisa dimengerti dan diterima (Galih Widjil Pangarsa, 2006).

Menurut Zahnd (1999) sebuah place dibentuk sebagai sebuah space jika memiliki ciri khas dan suasana tertentu yang berarti bagi lingkungannya. Selanjutnya Zahnd menambahkan suasana itu tampak dari benda konkret (bahan, rupa, tekstur, warna) maupun benda yang abstrak, yaitu asosiasi kultural dan regional yang dilakukan 
oleh manusia di tempatnya. Place yang baik dapat dilihat dari beberapa aspek seperti (Carmona, 2008) :

- Comfort : Diukur dengan lamanya seseorang tinggal di suatu tempat.

- Relaxation : merupakan pengembangan diri baik secara fisik maupun secara nonfisik.

- Passive Engagement : Dapat menciptakan suasana santai pada setting tempat secara natural.

- Activie Engagement : merupakan sebuah pengalaman langsung dari manusia terhadap suatu tempat.

\section{c. Desain Lingkungan (Environmental Design)}

Bagian penting dari desain perkotaan adalah kebutuhan untuk menyediakan kondisi yang nyaman di dalam ruang public. Tingkat sinar matahari, naungan, suhu, , kelembaban, hujan, angin dan kebisingan berdampak pada pengalaman dan penggunaan lingkungan perkotaan kita. Keputusan desain memiliki pengaruh penting dalam memodifikasi iklim mikro agar ruang lebih nyaman. Faktor yang relevan pada skala ini meliputi:

- Konfigurasi bangunan dan pengaruhnya terhadap dan hubungan dengan bangunan dan pengaruh lainnya di batas lokasi.

- Posisi jalan akses dan jalur pejalan kaki, pepohonan dan vegetasi lainnya, dinding, pagar, dan penghalang lainnya.

- Orientasi ruang internal dan eksternal dan fasad berkenaan dengan arah sinar matahari dan bayangan.

Dimensi Sosial Desain Perkotaan bisa didefinisikan sebagai hubungan antara ruang dan masyarakat. Beberapa aspek utama desain perkotaan:

a. Masyarakat Umum (Public Realm)

b. Kontrol Ruang Umum (the control of public space)

c. Keselamatan dan Keamanan (safety and security) 


\section{a) Public Realm (Masyarakat Umum)}

Ruang publik mempunyai arti sebagai suatu lokasi yang memiliki rancangan yang dirancang dengan seminimalnya, mempunyai akses tautan lingkungan sekitar, menjadi ruang pertemuan pengguna (manusia) dalam ruang publik dan berperilaku yang masyarakat yang sesuai dengan norma-norma setempat (Roger Scurton, 1984). Bidang publik memiliki dimensi 'fisik' (yaitu ruang) dan 'sosial' (yaitu aktivitas). Kehidupan publik melibatkan konteks sosial yang relatif terbuka dan universal, berbeda dengan kehidupan pribadi, yang akrab, akrab, terlindungi, dikendalikan oleh individu, dan hanya dibagikan dengan keluarga dan teman.Bidang publik dapat dianggap sebagai situs dan setting kehidupan publik formal dan informal. Konsep ranah publik fisik menjangkau semua ruang yang dapat diakses dan digunakan oleh publik, termasuk:

- Ruang publik eksternal - potongan tanah yang berada di antara tanah milik pribadi (misalnya kotak umum, jalan raya, jalan raya,taman, tempat parkir, hamparan garis pantai, hutan, danau dan sungai). Ini semua adalah ruang yang mudah diakses dan tersedia untuk semua orang.

- Ruang publik internal - berbagai institusi publik (perpustakaan, museum, balai kota, dll.) Ditambah sebagian besar fasilitas transportasi umum (stasiun kereta api, stasiun bis, bandara, dan lain-lain)

- Ruang publik dan kuasi eksternal - meski secara legal pribadi, beberapa ruang publik - kampus universitas, tempat olah raga, restoran, bioskop, teater, klub malam, pusat perbelanjaan - juga merupakan bagian dari ranah publik tetapi mencakup ruang publik eksternal yang diprivatisasi.

\section{b) Pengendalian Ruang (Controling of Public Space)}

Sementara menurut definisi, ranah publik harus dapat diakses oleh semua orang, beberapa lingkungan - secara sengaja atau tidak sengaja - tidak eksklusif dan tidak dapat diakses oleh bagian masyarakat tertentu. Jika kontrol akses dan pengucilan dipraktekkan secara luas, publisitas publik akan terganggu.

\section{c) Keselamatan dan Keamanan (Safety And Security)}

Orang menghadapi berbagai ancaman di lingkungan perkotaan - kejahatan, 'barbarisme jalanan'; Tindakan terorisme; Kendaraan yang bergerak cepat; Bencana 
alam / fenomena; Dan masalah yang tak terlihat seperti polusi udara dan kontaminasi air. Menciptakan rasa aman dan nyaman merupakan persyaratan penting dalam desain kota yang sukses.

\section{HASIL DAN PEMBAHASAN}

Ruang publik dimasa sekarang haruslah mempunyai fungsi lebih untuk menampung segala kebutuhan dan tuntutan terhap pola aktivitas yang ada didalam ruangnya (Puspasari, Ernawati, \& Suryasari, 2015). Alun-alun kudus merupakan lapangan luas yang berada pada tengah kota kudus. Alun alun ini kerap menjadi tempat berkumpul aktivitas anak anak muda seperti ekstrakulikuler. Disamping itu alun alun ini berfungsi sebagai sirkulasi Kota Kudus karena hampir semua jalan yang berada di kudus terpusat ke alun alun ini.

\section{- Gerakan (Movement)}

Gerakan sangat mendasar untuk memahami bagaimana fungsi tempat. Pejalan kaki mengalir melalui ruang publik di mana orang memilih duduk atau berlama-lama di ruang publik dan terkait dengan kehidupan dan aktivitas di dalam ruang. Pergerakan yang ada dialun alun kudus ini terbagi menjadi dua yaitu pergerakan manusia dan pergerakan kendaraan. Jika diteliti pergerakan manusia pada alun-alun kudus sangat acak seperti gambar berikut.
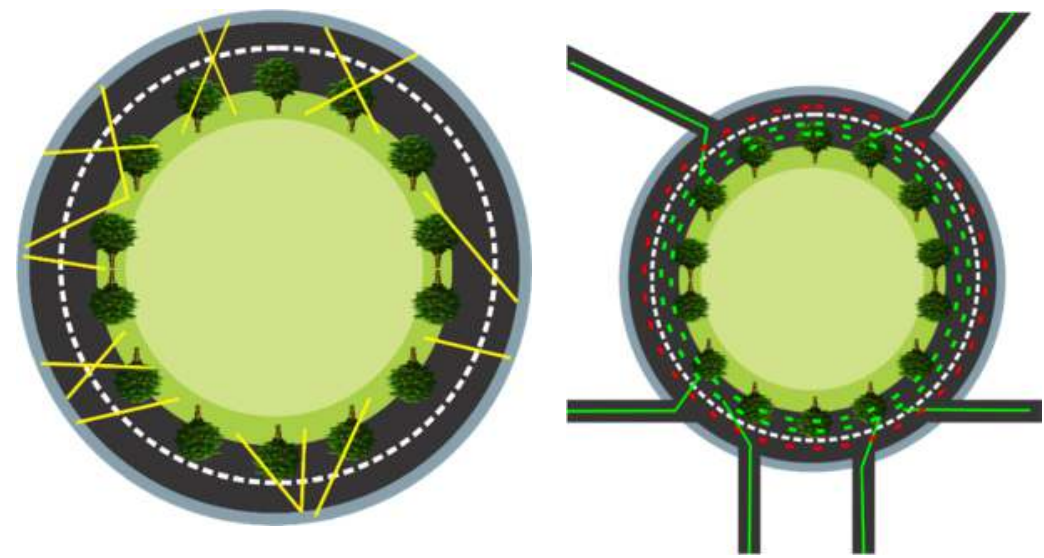

Gambar 2 Analisa pergerakan manusia (kiri) dan Kendaraan (kanan) di alun alun kudus Sumber : Analisa Pribadi, 2017

Terlihat bahwa pergerakan orang menyebrang sangatlah kacau dan tidak terdapat terdeteksi dengan rinci. Hal ini selain membahayakan dirinya sendiri juga 
membahayakan pengguna jalan raya di alun alun kudus ini. Sedang kan pada pergerakan kendaraan terlihat bahwa pergerakan nya masih normal akan tetapi jika mobil yang berada di bagian terdalam jalan mencoba untuk keluar akan sangat sulit, terkadang ini membuat sirkulasi tersendat. Biasanya jika orang kudus asli akan tau kemana jalur yang akan di lalui sehingga dari jauh jauh sudah berada pada jalur yang benar.

\section{- Desain Tempat Orang (Design of People )}

Jika diteliti alun alun kudus pada bagian sirkulasi nya terdapat banyak sekali street furniture yang dimana merupakan sebuah fasilitas yang di berikan oleh pemerintah kepada pengguna. Dengan jangkauan street furniture yang sangat dekat menambah minat masyarakat untuk memanfaatkan fasilitas tersebut. Element street furniture yang ada di alun alun kudus berupa tong sampah, kursi, gajebo, tempat duduk, taman dengan bagian sisi beton yang dapat digunakan sebagai tempat duduk.
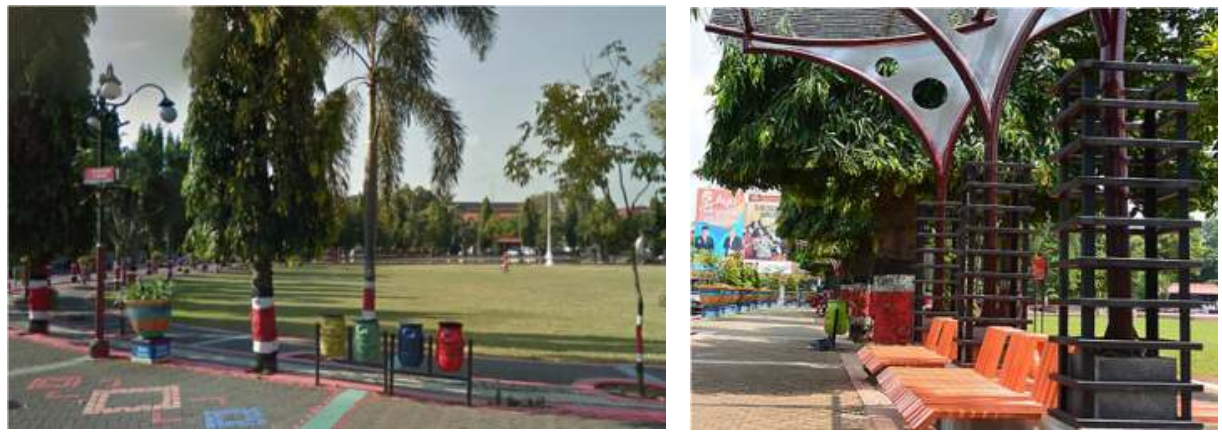

Gambar 3. Street Furniture Alun alun Kudus Sumber : Dokumentasi Pribadi,2017

\section{- Desain Suasana lingkungan (Environmental Design)}

Dalam membuat sebuah lingkungan penetrasi sinar matahari ke tempat-tempat perkotaan dan bangunan membuat tempat mereka lebih menyenangkan. Ini juga mendorong kegiatan di luar ruangan.Meningkatkan kesehatan, dan mendorong pertumbuhan. 

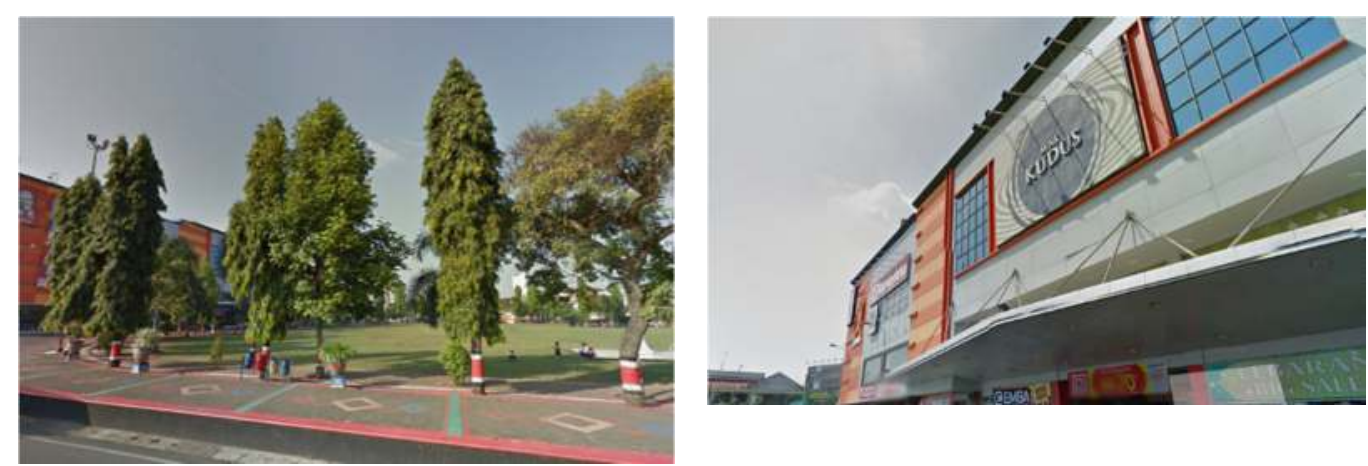

Gambar 4. Suasana di sekitar Alun-Alun Kudus

Sumber : Dokumentasi Pribadi,2017

Mall kudus merupakan salah satu mall yang berada di tengah kota, tepatnya berada di sisi barat alun alun kudus. Mall tersebut sangat ramai, terkadang masyarakat yang sembari berjalan santai di alun-alun berkunjung ke mall tersebut. Mall kudus pun mempunyai keterkaitan yang erat dengan alun-alun kudus. Dimana kedua tempat ini saling memberikan feedback dari masing masing fungsi.

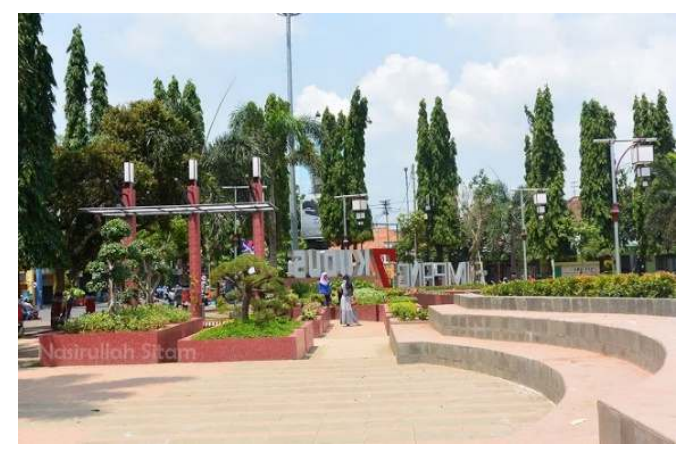

Gambar 5. Taman Alun-Alun Kudus Sumber : Nasirullah Sitam

Sedangkan suasana di dalam alun-alun kudus terlihat sangat tertata dengan rapi, berbagai macam elemen ada disini seperti akses jalan. Sirkulasi jalur pejalan kaki, berbagai macam pohon. Dengan sisi terluar taman yaitu sebuah pot bunga. Di taman ini tidak terdapat sebuah penghalang berupa pagar dan sebagainya. Orientasi eksternal lokasi alun alun berkenaan dengan arah sinar matahari.Terlihat bahwa sinar matahari menyinari bagian sisi timur. Hal ini menyebabkan jika pada siang saat menjelang siang, alun alun ini akan sepi pengunjung dikarenakan terik matahari yang membuat kawasan tersebut. 


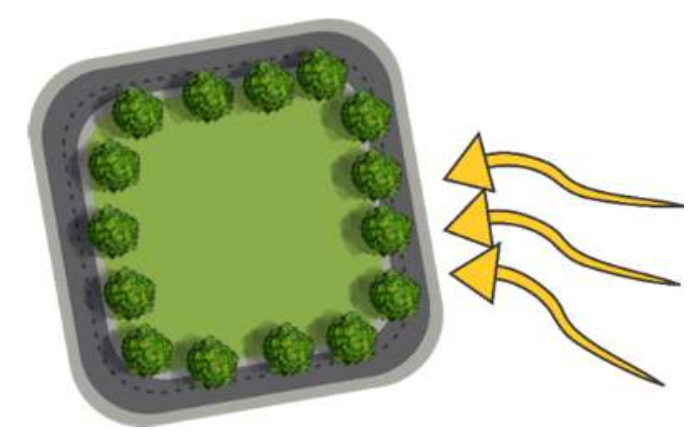

Gambar 6. Orientasi Arah Matahari Terhadap Alun Alun Kudus Sumber : Analisa Pribadi,2017

\section{- Ruang Masyarakat (Public Realm)}

Alun-alun terdapat setting ruang ruang yang didalamnya terdapat aktivitas dan peristiwa hubungan antar manusia. Sebuah public realm sendiri idealnya memiliki fungsi sebagai suatu forum untuk aksi-aksi politik dan representasi yang bersifat netral. Alun alun memiliki aksesible untuk digunakan oleh masyarakat umum.

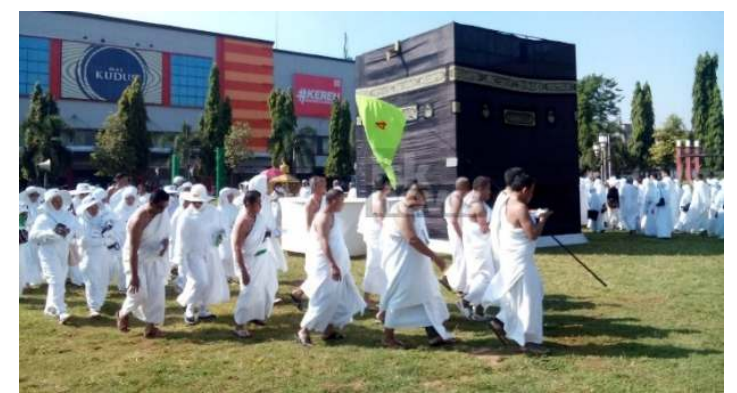

Gambar 7. Masyarakat kudus yang sedang latihan Towaft di alun alun kudus Sumber : IKSNEWS,2017

\section{- Pengendalian Ruang (Controling of public space)}

Alun alun kudus merupakan alun alun yang dikelola oleh pemerintah daerah Kabupaten Kudus. alun alun sendiri bebas dari pihak pihak tertentu yang secara sengaja maupun tidak sengaja menguasai alun alun kudus. tidak ada larangan apapun di dalam kawasan ini, tidak mendriskrimnasikan sesuatu yang menurut etika tidak benar.

Pada alun alun ini tidak terlihat kelompok kelompok yang meresahkan. Kebanyakan orang yang berkungjung kemari untuk melakukan event tertentu atau sekedar lari sore atau pagi. Pengedalian alun alun sendiri terawasi oleh pos polisi yang berada pada sisi barat sebelah mall kudus. 


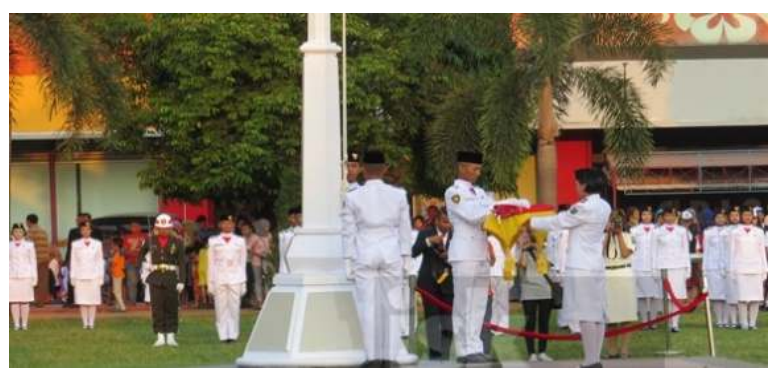

Gambar 8. Upacara 17 Agustus

Sumber : IKSNEWS,2017

\section{- Keselamatan dan Keamanan (safety and security)}

Alun alun memiliki berbagai macam pengunjung yang tidak teridentifikasi latarbelakang nya.dengna desain alun alun yang dapat dilihat dari segala arah membuat alun alun kudus ini terlihat sangat aman dari tindak criminal. Akan tetapi untuk safety nya alun alun ini cukup berbahaya untuk anak yang bermain tanpa pengawasan karena alun alun kudus berdampingan dengan sirkulasi mobil dan motor. Sehingga keadaan ini membuat para pengguna juga perlu waspada.

\section{KESIMPULAN DAN SARAN}

\section{Kesimpulan}

Berdasarkan hasil analisa dapat diketahui bahwa kota kudus memiliki berbagai macam kawasan yang dapat di teliti seperti kawasan kudus kulon dan kawasan alunalun sebagai studi kasus untuk pendekatan functional dimension dan social dimension yaitu

- Dimensi Fungsi

Membahas dimensi fungsional desain perkotaan, memberikan wawasan pentingnya memahami desain perkotaan sebagai proses perancangan. Dalam proses mendesain estetika, fungsinal, teknis dan kenyamanan harus sesuai dengan fungsi bangunan itu sendiri. Untuk itu desain harus totalitas dan dapat mencakup fungsi fungsi bangunan sekitar, sehingga membuahkan saling memberikan timbal balik.

- Dimensi Sosial

Dimensi sosial memunculkan sejumlah permasalahan yang terjadi dari dampak desain alun alun kudus seperti keamanan dan keselamatanya. Bahaya disekitar alun alun kudus seperti mobil dan kendaraan lain. Di karenakan alun alun kudus berada di pusat 
kota dimana semua kendaraan berpusat disini dan berjalan dengan cepat. Saran untuk pengguna yaitu selalu waspada akan sekitar.

\section{Sarana}

Saran dari hasil dimensi fungsi dan sosial adalah mempertahankan desain kawasan sesuai dengan dimensi fungsional desain perkotaan. Hal ini dilihat dari banyaknya kegiatan dimensi sosial yang ada di kawasan penelitian, tidak hanya aktivitas harian namun juga aktivitas event-event tahunan yang dilaksanakan di kawasan penelitian. Aspek demensi sosial yang harus diperhatikan kembali adalah posisi alunalun yang berada di tengah jalan sehingga perlu adanya pengaturan sirkulasi pergerakan orang, kendaraan dan penyebrangan.

\section{DAFTAR PUSTAKA}

Affan Satrio Nugroho, Agus Suryono and Setiawan, Andhy. (2010). Analisa Alun Alun

Kota Purworejo. Dalam Tugas Akhir Arsitektur Universitas Diponegoro

Carmona. (2008). Public space: the management dimension. Routledge, Taylor \& Francis group. New York, USA

Bintarto. (1989). Interaksi Desa-Kota dan Permasalahannya, Jakarta: Ghalia Indonesia

Darmawan, Edy. (2007). Peranan Ruang Publik Dalam Perancangan Kota, Semarang: Badan Penerbit Universitas Diponegoro

Graaf, H.J. de. (1998). Cina Muslim di Jawa Abad XV dan XVI antara Historisitas dan Mitos, terjemahan dari Chinese Muslims in Java in the 15th and 16th centuries: The Malay Annals of Semarang and Cirebon, Yogyakarta: PT Tiara Wacana.

http://www.isknews.com/ diakses pada Januari 2018

http://www.penataanruangjateng.info diakses pada Januari 2018

Nasrullah, R. (2015). Internet dan Ruang Publik Virtual, Sebuah Refleksi atas Teori

Ruang Publik Habermas. Jurnal Komunikator, Vol 4, Nomor 1, 33-45.

Nugroho, A., Cahyono. (2009). Kampung Kota Sebagai Sebuah Titik Tolak Dalam

Membentuk Urbanitas Dan Ruang Kota Berkelanjutan. Jurnal Rekayasa, Vol 13, Nomor 1, 209-218

Pangarsa, Galih W. (2006). Merah Putih Arsitektur Nusantara, Yogyakarta : Andi 
Puspasari, R., Ernawati, J., \& Suryasari, N. (2015). Pola Aktivitas Pada Ruang Publik Taman Bungkul Surabaya. Jurnal Mahasiswa Jurusan Arsitektur, Vol 4, Nomor $2,17-24$.

Hakim, Rustam. 2004, Arsitektur Lansekap, Manusia, Alam dan Lingkungan. Jakarta : Bumi Aksara

Santoso, E. B. (2008). Studi Perencanaan Penataan Kawasan Alun-Alun Kota Brebes. Jurnal Teknik Sipil Dan Perencanaan, Vol 10, Nomor 2, 151-160.

Sardjono, Agung. Rochma Harani, Arnis. (2017) Sacred Space in Community settlement of Kudus Kulon, Central Java, Indonesia. IOP Conference Series: Earth and Environmental Science Vol 99, 1-6

Scurton, Roger. 1984, The Meaning of Conservatism, London : Macmillan Publishers Limited

Zahnd, Markus,1999, Perancangan Kota Secara Terpadu, Teori Perancangan Kota dan Penerapannya, Semarang : Kanisius.

Zahra, A. F., Pertanian, J. B., Pertanian, F., Brawijaya, U., Beauty, S., \& Rayman, M. (2014). Evaluasi Keindahan Dan Kenyamanan Ruang Terbuka Hijau ( RTH ) Alun-Alun Kota Batu the Evaluation of Beauty and Comfort At Green Open Space Batu City Square. Jurnal Protan, Vol 7, Nomor 2, 524-532.

Zhang dan Lawson. (2009). Meeting and greeting: activities in public outdoor spaces outside high-density urban residential communities. Urban design international, vol 14, Nomor 4, 207-214 